accepted as causal factors in the spread of the disease: contagion from person to person, contaminated food-supply, wearing apparel, \&c., rats, fleas, and other animals. That rats have always played a very important part in the spread of plague is no new theory. A Puranâ written over 800 years ago in India runs as follows: "When you notice an unusual mortality amongst rats it is a sure sign that you are shortly to be visited by a fatal disease, and your only safety lies iu flight." Early in the present epidemic the natives learned to associate the connexion between rats and plague. In 1905 I carried out a series of experiments to prove the connexion between rats and fleas in the spread of plague. I had done one or two experiments in 1901 but had not the time or opportunity then to go fully into the matter. In 1900 and 1901 from observations and experiments it seemed very clear that rats and fleas were two leading factors in the local spread of the disease. Food-supply, especially grain, has always in my mind been accountable for the spread of the disease, but chiefly amongst rats. Experiments carried out in 1902 and afterwards in 1904 and 1905 corroborated the previous conclusions. On the above supposition I have always divided plague into the classes bubonic, pneumonic, and alimentary. In an article published in THE LANCET of June 10th, 1905, p. 1562, I gave this latter division and my reasons for thinking so. In the first years of the present epidemic all foodstuff that was found in infected go-downs was either destroyed or exposed to the sun for several days. This was only a measure, however, carried out in one or two places and in my opinion should be much more enforced.

There can be nothing but praise for the strenuous efforts made by the various Governments in India to stamp out the disease and prevent its spread, but it has always seemed that too much weight is given to certain lines of action even after the results were there to prove their faultiness. Then, again, too much importance is given to various methods of inspection and segregation employed in certain places where plague has not made headway. To say, for instance, that railway inspection and notification have kept Madras city free from plague is asking one to accept too much for these precautions. It is one of the puzzles connected with this disease that have still to be answered. Black Town, in Madras city, in about as favourable a locality for the disease to thrive in as one could seek for. Plague cases have occurred there, but the disease has never made headway. Why? Take Calcutta. Plagne should have swept the city but it has not. There are still several questions which require answering before we can get to the bottom of the periodical recrudescence and disappearance of this disease. And because Madras and Calcutta are free to-day it by no means follows that they will remain so for ever. Several districts lived under that false impression for one or two years, only to feel the scourge more acutely when it did come. There is one important district in Mysore State in which plague, at least during the past two jears, has been a more or less minus quantity. That is on the Kolar Gold Fields. Plague used to visit the fields regularly almost every year. The dislocation to the work can be well imagined. The part of the fields where the coolies live is about nine miles long by about one wide. The coolies live in tattie huts erected in long parallel rows. Each hut stands by itself. If a case of plague occurred in one of these huts it was pulled down and burned. The inhabitants were segregated and the adjoining huts were also evacuated. These precautions no doubt curtailed the disease to a certain extent but the disease ran its course. In 1904 it was decided to commence at the north end of each camp and go right through, digging up the floor of each hut and destroying all the rats. When this was done the performance began all over again. This was carried on through 1905 and 1906; in addition in the latter year "Liverpool rat virus" was laid down all over the fields, commencing at one end and going clean through. It so happened that in the extreme north end was a closed.down mine and the virus was not laid down in that quarter. Within a fortnight of the experiment word was brought to the "Lab." that many rats were making their way to the north end of the field and one or two were found dying in outhouses. From these dying rats I was able to isolate a bacillus identical in every way with the original Liverpool rat virus bacillus. The outbreaks of plague on the fields have become less and less. Isolated cases have occurred, but the disease has never spread to any extent since these two plans have been carried out. Yet in the neighbouring villages, which abut on the fields, plague is constantly occurring. In towns and villages it would be impossible to carry out the former of these two methods to any extent, but the use of the "Liverpool rat virus" might be extensively used in conjunction with other exterminators. The results on the gold fields appear so satisfactory that they are worthy a more extended trial.

Haffkine's prophylactic should be pushed more than it is. Unfortunately, it has not found favour with the whole of the medical profession in India and in Madras Presidency it has not been used very much for that reason. It is also supposed only to confer immunity for at most six months or so. This belief has told against its use in many places. There is, further, a widespread impression amongst the natives that it produces impotence. Now, if we have a considerable portion of the public in Great Britain objecting to vaccination and allowed by Government to carry out their objection to the point of refusal, thereby building up an ever-increasing population of unprotected individuals until one day we have a general and widespread outbreak of smallpox, how can we afford to laugh at the uneducated Indian because he will not come forward for inoculation? The problem is not an easy one, but it is one that must be tackled. This yearly death roll is becoming a very serious matter. Plague has long ago ruined the trade of Bangalore; Poona has suffered and is still suffering; the Punjab is in a pitiful condition; at any moment the disease may break its present bounds and flow over the Straits Settlements and Ceylon and the consequences are not difficult to conceive.

The treatment of plague has not made much advance during the past years. Various sera bave been tried with disappointing effects. Carbolic acid injections have done good in many cases and at one time it was thought that it would prove very efficacious. Adrenalin has been boomed, but cardiac stimulants are still the chief mainstay. There is one drug which so far I have not seen mentioned and which I used in 1906 on four or five cases with remarkable results. This is collargol, an allotropic form of silver. It is soluble in water about 1 in 25. I used it in intravenous injections, one cubic centimetre of a 1 per cent. solution. The first case was hardly a fair test, but the result was astonishing.

A man was admitted into the plague hospital about 8 A.M. He had double cervical buboes. His temperature was $104 \cdot 6^{\circ} \mathrm{F}$. and his pulse was 130 . He was highly delirious and death seemed imminent. So hopeless was his condition that at first I refused to try the drug. However, I gave one cubic centimetre of a 1 per cent. solution intravenously; this was at $9.30 \mathrm{~A}$.M. I called down again at 5 P. M. The temperature was $100^{\circ}$ and the pulse was 105 . The wild delirium was gone but he was picking at his blanket. It was evident that the bronchial glands were infected, also the apices of his lungs. I repeated the injection. Next morning his temperature was normal, his pulse was 105, and he was able to answer questions. I did not repeat the injection. His breathing was very laboured and the upper portion of his lungs was quite dull. He died on the following day. The necropsy showed infiltration of all the cervical glands, bronchial glands, and consolidation of the upper and middle lobe of the right lung and upper lobe of the left. I felt satisfied that the drug had had a beneficial effect on this man's case. Had he not received it I am sure that he would have died the same day.

The next two cases were men with inguinal buboes. They had been ill 24 hours previous to admission. They had temperatures over $101^{\circ}$; the buboes were exquisitely painful. I gave both intravenous injections of one cubic centimetre of a 1 per cent. solution in the morning; by evening their temperature was normal. The injection was repeated next morning. The temperature never rose again and the buboes disappeared in three days, both men being up and about on the eighth day. The other two cases were in children. I was unable to do intravenous injection and after two days' illness both died. The drug, I think, merits further trial. I was not in charge of the plague camp and it was only by the courtesy of the native doctor that I was allowed to carry out this treatment. I am, Sirs, yours faithfully, Cliveden-place, S.W., August 12th, 1907.

$$
\text { AleX. M. ELLIOT, M.B. Edin. }
$$

\section{THE GEOGRAPHICAL DISTRIBUTION OF HERNIA.}

To the Editor's of THE LANCET.

SIRS,-Dhough I was well aware that abdominal hernia is a complaint common to all nationalities I was not sure whether the varieties we are familiar with in this country 
were also met with amongst other and less civilised communities. During the early part of this year I wrote to medical men practising in various parts of the world, asking them if they would kindly inform me as to the frequency with which hernia was met with amongst the native races in their respective districts. The information very kindly furnished me is of considerable interest, and it would appear that hernia has not only a wide geographical distribution but that the more common varieties as seen in this country prevail all over the world. It is somewhat remarkable that femoral hernia is so seldom met with in certain districts. The influence of employment as regards the incidence of hernia is also clearly brought out. The following are some of the letters I have received:-

\section{Dr. G. Duncar Whyte of Swatow, China.}

Hernia is of frequent occurrence in this neighbourhood, mostly inguinal, and usually on the right side. For example, a hospital here bought five and a half dozen trusses for right inguinal hernia. and only one a half dozen for the left side. Nut of, roughly speaking, 15,000 patients I have seen in China I have only once diagnosed a femoral hernia. I have not heard of anyone here or in Swatow who stocked trusses for femoral hernia. Last year I saw a curious case in which there was a very small hernia in the linea alba, midway between the xiphi-sternum and the umbilicus. There had been neither injury nor disease locally and the same condition had existed in the patient's father and (paternal) grandfather. About eighteen dozen trusses are sold in Swatow in the course of a year, a town with a population of 20,000 by night and 30,000 by day. The extra 10,000 come in from al the villages around to earn their living by coolie work, \&c. Tight prepuces are common and the straining to express urine may bs expected to accentuate any congenital defect that exists. The Chinaman would not dream of having his foreskin cut any more than most of them will consent to have extra digits removed ; they wish to preserve their whole body complete. They all " hunker" to defæcate, an attitude which by supporting the walls of the inguinal canal, or by securing that a man shall only defæcate when his hernia is reduced may diminish the chances of strangulation, but to my mind this attitude does not have that influence upon the incidence of hernia which I was led in my student days to anticipate. On the other hand, its causal relation to hæmorrhoids and more markedly to prolapse of the rectum seems to me beyond question.

\section{Dr. A. Sims of Matadi, Congo State.}

Hernia is most common here. I should think 3 to 5 per cent. of the adult male population is affected with it. Formerly, when there was no railway and all goods were carried to the interior on men's heads, hernia was more common than now and strangulated hernia was very common. Native products are now only carried, at least in these parts for short distances, and in consequence hernia is diminishing. Child labour for carrying burdens is growing less and as a result I see fewer labour for carrying burd

Mr. Malcolm A. Smith of Bangkok.

I should consider hernia to occur as frequentiy here as it does in England. I have, however, in five years' practice never seen or heard of a case of strangulation of the bowel.

Mr. B. Granvill Corney of Fiji.

From personal observation I can say that inguinal hernia is of common occurrence amongst the members of the Fijian race. Umbilical hernia is also very frequently met with in Fijian children, though it usually becomes less apparent as they grow up. I have seen one case of obturator hernia in a boy of 12 or 14 years of age.

\section{Mr. A. J. GLANVILle Barker of Sarawaz, Borneo.}

Hernia is fairly common amongst all the races we see here-viz. Malays, Dyaks, Chinese, and Indians.

\section{Dr. Edward H. Armitage of Honolulu.}

The following statistics have been furnished to me by the surgeon to the Queen's Hospital in Honolulu. From June 1st, 1904, to May 13th, 1907. Total number of cases operater upon, 54. Nationality : Hawaiian, 7 ; part Hawaiian, 2; other nationalities, 45. Varieties-inguinal: single, 40 ; double, 8-total, 48 ; femoral : single, 5 ; double, 1 -total, 6 . Sex-Male: inguinal, 46 ; femoral, 4-total, 50 . Female: inguinal, 2 ; femoral, 2-total, 4. Strangulated, 3; non-strangulated, 51.

I am, Sirs, yours faithfully,

R. W. MurraY, F.R.C.S. Eng.,

July 17 th, 1907

Surgenn, David Lewis Northern Hospital, Liverpool.

\section{THE DISCUSSION ON ACUTE NEPHRITIS IN CHILDREN AT THE BRITISH MEDICAL ASSOCIATION. \\ To the Editors of THE LANCET.}

SIRs,-May I puint out that your report of my remarks on acute nephritis in children on p. 390 of THE LANCET of August loth is misleading. The gist of my statement was that ocular manifestations were conspicuous for their absence in acate nephritis. Amaurosis without ophthalmoscopic signs occurs as in adults. The typical picture of albuminuric retinitis-neuro-retinitis with a star-shaped figure at the macula-which occurs rarely in cases of intracranial pressure without renal disease in adults, is relatively common in these cases in children.

August 9th, 1907.

I am, Sirs, yours faithfully,

** We have much pleasure in inserting Mr. Parsons's correction. Our reports have to be somewhat condensed and hence there is always a liability to ambiguity.-ED. L.

\section{EXPERIMENTS ON PROLONGED PROTEIN FEEDING.}

To the Editors of THE LANCET.

SIRs,-In a criticism of my paper on protein feeding Dr. Chalmers Watson expressed the opinion that more than one of the thyroid glands therein illustrated are patbological and not as I stated normal, but to my request for enlightenment as to what points he relied on in forming this opinion he has replied that he prefers to postpone giving any reasons. Seeing that the criticism is one which, if substantiated, would materially affect one of the conclusions of my paper $I$ hope Dr. Watson will appreciate the desirability of supporting his statement by some facts, however brief.

I am, Sire, yours faithfully,

Harley-street, W., August 10th, 1907. DAVID FoRsYTH.

\section{INTERNATIONAL CONGRESS ON SCHOOL HYGIENE.}

To the Editors of THE LANCET.

SIRS, - I attended all the general meetings of this important Congress and I spent many hours in Sections II., VIL., and $\mathrm{X}$. during the past week, but with the exception of a passing reference by Mr. L. M. Bowen.Jones of Carmarthen on Friday the Sunday schools were not mentioned (to my knowledge) either in any set paper or by casual debaters. The entire omission of Sunday schools from the programme of a congress on school hygiene is a curious fact and difficult to account for. As far as my own experience goes Sunday schools are frequently the foci and hotbed of infections diseases and any closure of day schools will be useless unless accompanied by that of the Sunday schools in the same district. It is true that the scholars are only in the Sunday schools for from one hour to one and a half hours once or twice in the day, but the buildings are often much overcrowded, badly lighted, insufficiently ventilated, and otherwise ill adapted for their purpose.

I consider that the powers of the local sanitary authority for dealing with Sunday schools are not so stringent and easy of application as they ought to be, for some types of Sunday school managers are not gifted with common sense and they can only be influenced and made to do right by the exercise of legal powers strictly applied.

I am, Sirs, yours faithfully,

SIDNEY C. LAWRENCE,

Medical Officer of Health and Delegate from Edmonton, August 12th, 1907 . Edmonton.

\section{AN ASSOCIATION OF SHIP SURGEONS: 7o the Editors of THE LANCET.}

SIRs,-Would you allow me through the medium of your valuable columns to issue an appeal to all ship surgeons, both past and present, urging them to join the B.S.S.A. (British Ship Surgeons' Association), which is being formed with a view to improving the "status" of medical officers to shipping companies and also to obtain more "clinical" and "experimental " evidence on the treatment of "sea-sickness" and other "affections" peculiar to sea-going persons. It is proposed ultimately to issue a Ship Surgeons' Gazette monthly, that is, if the membership permits. We have every reason to believe that it will have the substantial support of all shipping companies, seeing that it will indirectly further their interests. Further particulars can be obtained from, and application for membership to be sent to, Yours faithfully,

G. METCALFE-SHARPE, Surgical Officer.

Angram Hospital, Middlesmoor, Leeds, August 8th, 1907. 